\title{
Design and Construction of a Solar Hybrid Car (Electric Motor and Human Propulsion)
}

\author{
Edgar A. Salazar ${ }^{1}$, Juan F. Arroyave ${ }^{1}$ and Felipe Gómez ${ }^{2}$ \\ 1. Technology Faculty, Department of Mechanical Technology., Technological University of Pereira, C.P 660003, Colombia \\ 2. Mechatronic Engineering, Technological Faculty, Technological University of Pereira, C.P 660003, Colombia
}

Received: September 21, 2016 / Accepted: September 28, 2016 / Published: January 31, 2017.

\begin{abstract}
This work presents the design and the construction of a solar hybrid vehicle whose principal driving force is a photovoltaic system, assisted by human propulsion. The solar race of Atacama Desert (Chile) was the first challenge that the solar vehicle faced, with a maximum catchment area of $4 \mathrm{~m}^{2}$ storage 1,500 Wh and a maximum cost of 7,000 USD. Built vehicle was tested, reaching speeds on flat terrain of $40 \mathrm{~km} / \mathrm{h}$ with engine and $50 \mathrm{~km} / \mathrm{h}$ with human-powered contribution. Proposed design could be projected as a vehicle for transporting person average Latin American roads.
\end{abstract}

Key words: Renewable energy, sustainable transportation, solar vehicle, embedded electrical motor.

\section{Introduction}

Transportation at global level remains a major contributor to greenhouse gas emissions, recently developed technologies have tried to diversify the types of energy sources in vehicles: hydrogen fuel cells, electric motors, hybrid generation, natural gas, etc. Colombia is experiencing a transition into the renewable energy sources, where the sustainable transportation becomes one of potential lines of development. The electric vehicles and in particular solar cars are an interesting alternative in terms of sustainable transport. However, the great challenge comes in high load demands (torque and power) due to high slopes, acceleration and starts.

Human-powered vehicles have attracted interest for many years; the association WHPVA (World Human Powered Vehicle Association), an international federation that promotes the development of "human-powered vehicles" and organizes sporting events mainly in Europe. Although most of their work

Corresponding author: Edgar A. Salazar, Ph.D., professor, research fields: fluid power and renewable energy. is related to the development of the "bicycle" (particularly the recumbent, being the fastest), also promotes research on vessels and aircraft or "blimps" human-powered. Similarly different competitions around the world as the World Solar Challenge in Australia or Chile's Atacama Desert have motivated scientists and academics to innovate with solar and hybrid vehicles becoming more efficient, promoting a culture for sustainable transport. Electric bikes have become a pole of development. Motors embedded in the drive wheel give high flexibility to deploy other alternatives traction. A photovoltaic panel as a power source for the motor and human power from the pilot may be perfectly complementary power sources. The human propulsion can be used in load solicitations (torque, speed) of the electric motor during inefficient operations.

\section{Design}

The design involves several systems, namely: chassis, suspension, steering, fairing, traction and electrical system [1, 2]. This publication is intended to emphasize the power and traction systems and the way they interact. 


\subsection{Determination of the Required Power}

Power demand $(\dot{W})$ in a moving vehicle is defined by the product of overall strength and reached speed. The total force $F_{T}$ is defined by the sum of all the resistive forces [3-5]: Force due to the slope $F_{\theta}$, tire rolling resistance $F_{r}$, and force by aerodynamic effects $F_{a}$. Fig. 1 presents these loads, $W$ represents the total weight of the vehicle and $\theta$ the slope.

With direction of motion and using Newton's Second Law, the total traction force required by the load is obtained.

$$
F_{T}=W \sin \theta+C_{r} W \cos \theta+\frac{1}{2} \rho S K_{a} V^{2}+m a
$$

where, $C_{r}$ is rolling coefficient which depends on the friction between road-tire and the pressure of tire, $K_{a}$ is coefficient of aerodynamic restriction which depends on airfoil and the relative wind speed against the vehicle, $S$ is transversal section of vehicle perpendicular to the direction of movement, $\rho$ (wind density), $m$ (mass) and $a$ (acceleration). Acceleration as the inertial effects (acceleration causes the inertial force by the principle of Da Lambert) significantly influence on the total force required by the drive wheel. Power will be determined by:

$$
\dot{W}=\left(W \sin \theta+C_{r} W \cos \theta+\frac{1}{2} \rho S K_{a} V^{2}+m a\right) \times V
$$

With this expression can be analyzed the influence of each component on the total power demand.

Assumed parameters: $C_{r}=0.01, S=1 \mathrm{~m}^{2}, K_{a}=0.2$, $m=200 \mathrm{~kg}$.

It can be seen that the vehicle (moving to $30 \mathrm{~km} / \mathrm{h}$ ) will require $1,800 \mathrm{~W}$ on slopes of $10 \%$, but only $220 \mathrm{~W}$ on flat ground. With steep slopes, the component $W$ $\sin \theta$ is the most influential, but on flat surface the rolling and aerodynamic effects (at high speeds) are predominant. Mass is the most influential to accelerate and overcome inertia. A driving torque from the power unit is required to put the vehicle in motion. This torque will depend on the total force (Eq. (1)) and the driving wheel $R_{T}$ (Eq. (3)).

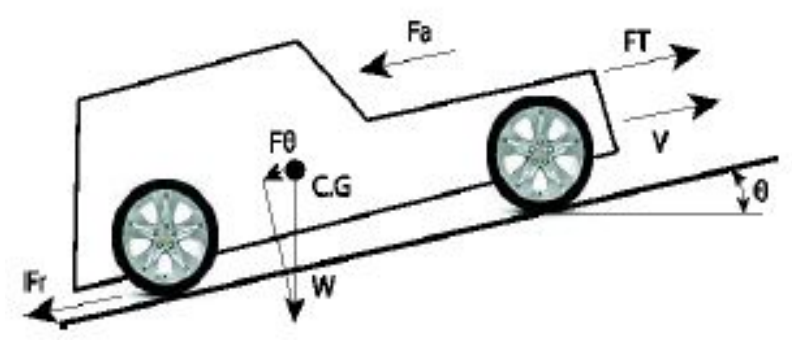

Fig. 1 Forces in moving vehicle.

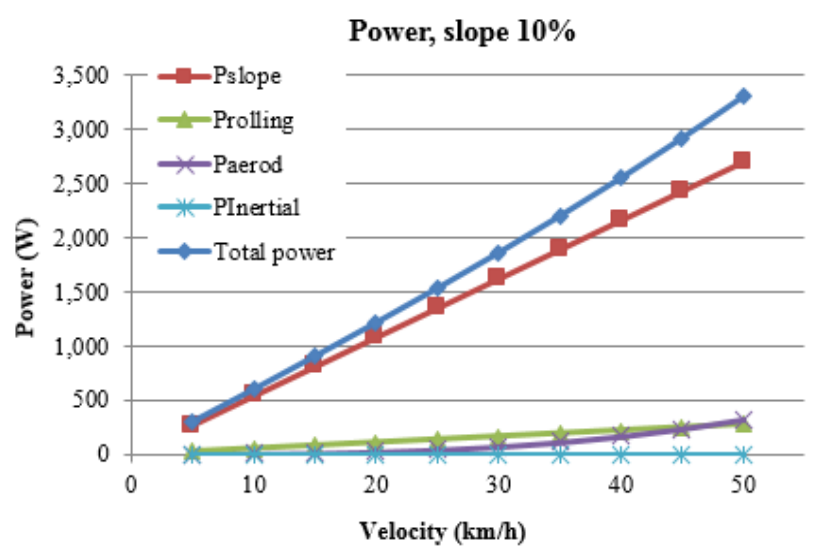

(a)

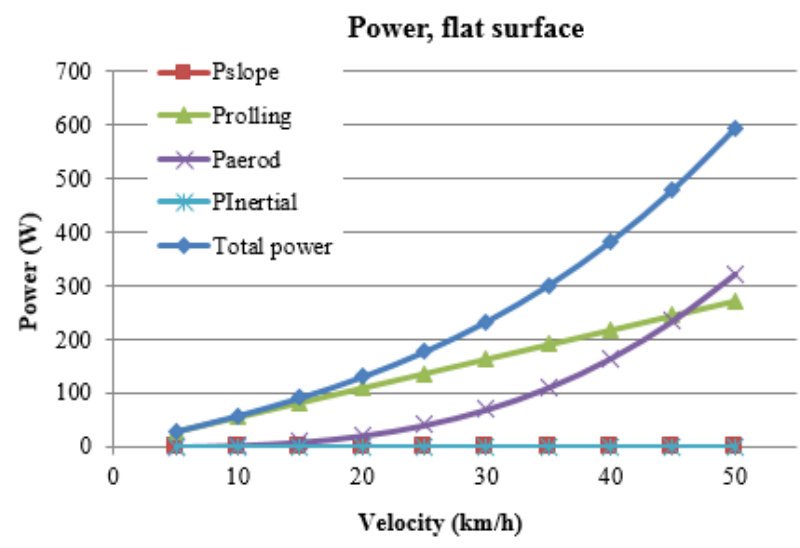

(b)

Fig. 2 Power components, inclined and flat surfaces.

$$
T_{T}=\left(W \sin \theta+C_{r} W \cos \theta+\frac{1}{2} \rho S K_{a} V^{2}+m a\right) R_{T}
$$

\subsection{Electrical Motor}

A $2 \mathrm{~kW}$ engine was selected for the vehicle and embedded to the driving wheel. The performance curves are recorded in Fig. 3.

Fig. 3 also includes torque and power curves (Eqs. (2) and (3)) on $10 \%$ slope. Traction wheel diameter is 26 


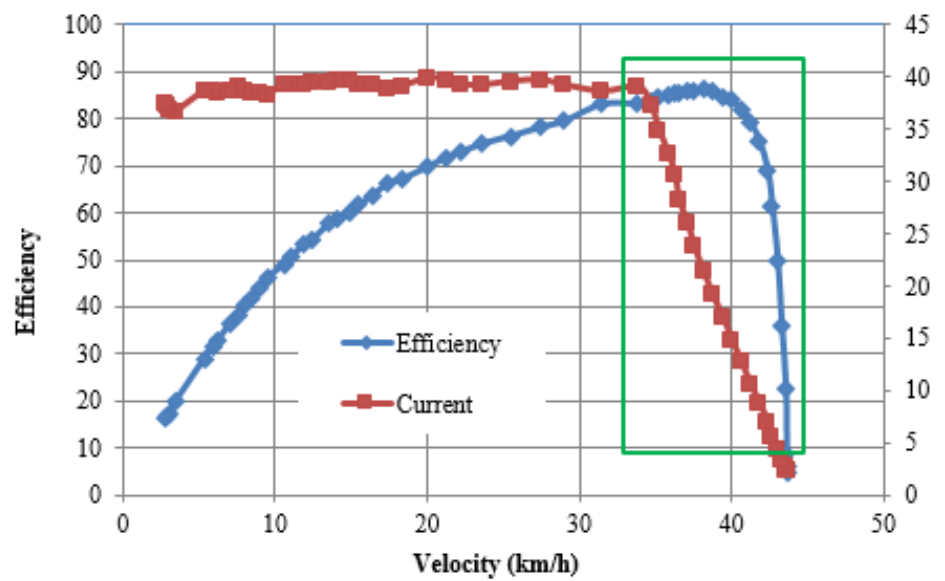

\section{善}

(a)

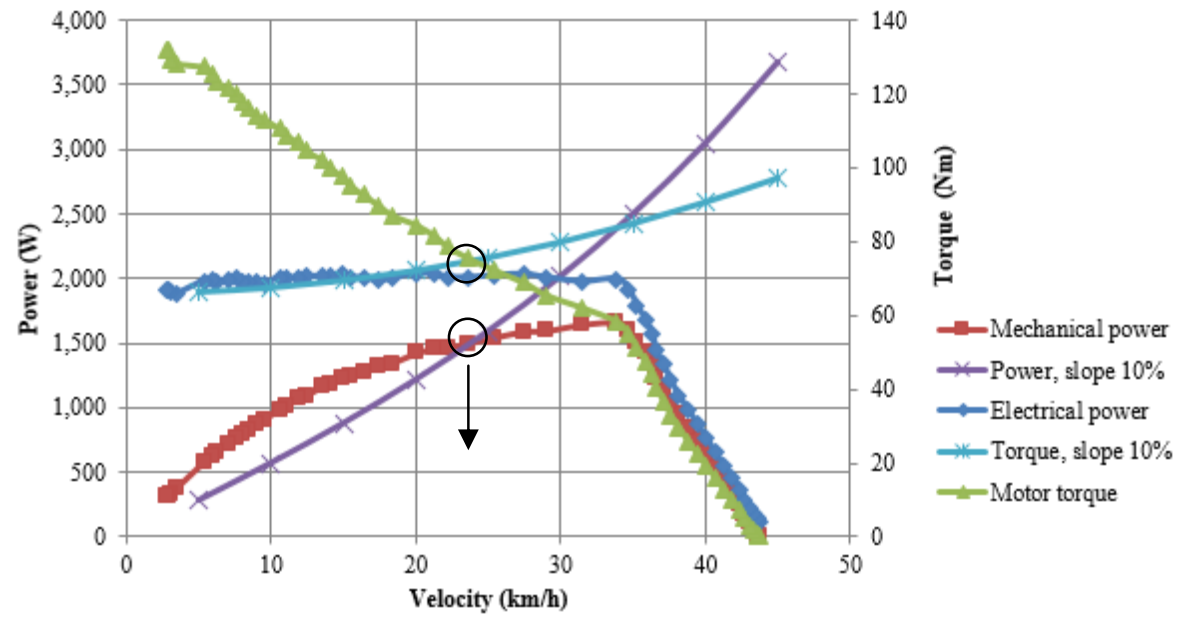

(b)

Fig. 3 Development curves of motor.

inches $\left(R_{T}=13 \mathrm{in}\right)$. The circles show the motor operating point. In the aforementioned load demands, the vehicle reaches $24 \mathrm{~km} / \mathrm{h}$ with efficiency of $75 \%$, however on flat roads it will be able to reach $42 \mathrm{~km} / \mathrm{h}$ with maximum efficiency.

\subsection{Human Propulsion}

Pilot of vehicle can give extra power when required. According to transmission relation, driver would deliver high torque at low velocity or vice versa. Fig. 4 presents a scheme with the gears employed in transmission.

There are 384 possible combination of transmission relation with a maximum gain of 4.54. Osorio et al. [6] have shown that a normal person is able to deliver a force of $300 \mathrm{~N}$ over pedal in a bicycle with a connecting rod of $17 \mathrm{~cm}$ length, keeping a velocity of $1.2 \mathrm{rpm}$. This represents a torque of $51 \mathrm{Nm}$ and approximately $390 \mathrm{~W}$.

\subsection{Conception of Vehicle}

Fig. 5 presents the 3D design and the actual vehicle during Solar Atacama Rally.

\section{Conclusions}

A hybrid vehicle was designed and built with a combined power system consisting of electrical motor embedded in the rear driving wheel and mechanical transmission. Electrical Power Sources are composed by 2 photovoltaic panels of $350 \mathrm{Wp}$ each one and 2 lithium batteries of $48 \mathrm{~V}$ DC and 20 Ah each one. Pilot is able to deliver additional power of $400 \mathrm{~W}$, and torque 


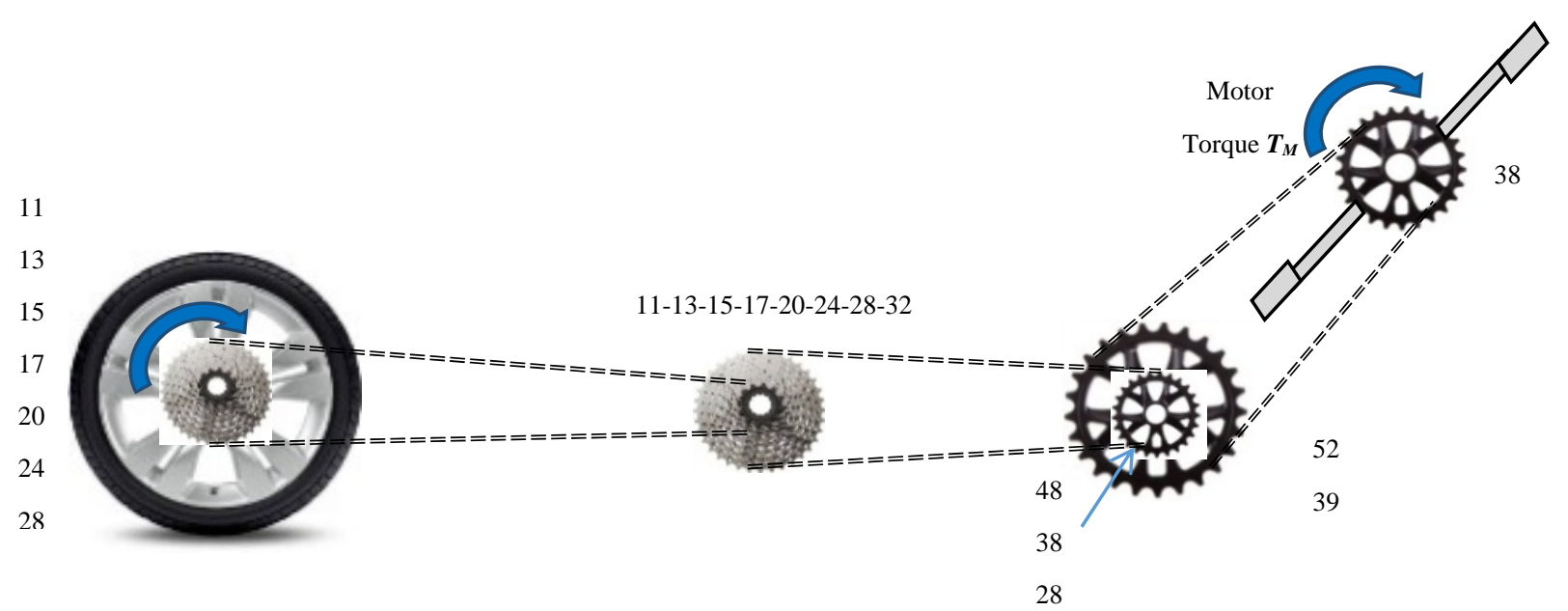

Fig. 4 Transmission relation in vehicle.

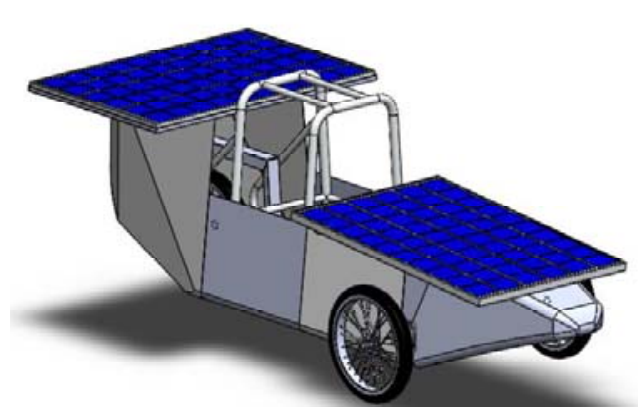

(a)

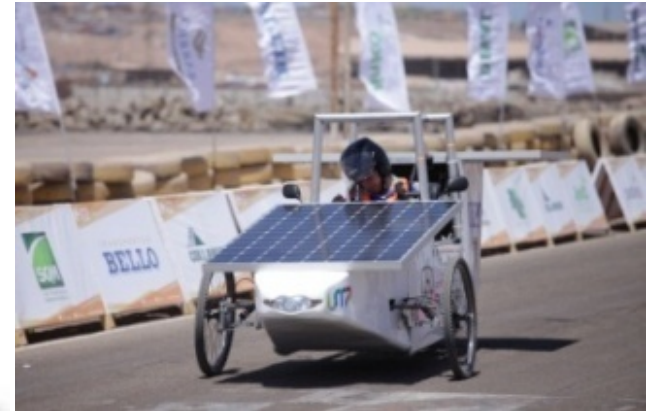

(b)

Fig. 5 Vehicle XU, design and final prototype.

of $230 \mathrm{Nm}(51 \mathrm{Nm} \times$ Gain) at low velocities. This is very useful in starts and sudden acceleration.

Tests over vehicle showed a maximum speed reached of $40 \mathrm{~km} / \mathrm{h}$ on flat roads and it increased until $50 \mathrm{~km} / \mathrm{h}$ with high velocity relation.

Since many years ago different studies have tried the interaction between human traction and electric motor $[7,8]$.

\section{Acknowledgement}

Some enterprises were sponsors of this project such as Busscar of Colombia, CFC Constructors and especially Technological University of Pereira.

\section{References}

[1] Pahl \& Beitz. 2007. Engineering Design. 3rd ed. London:

\section{Springer.}

[2] Cross, N. 2008. Engineering Design Methods. Strategies for Product Design. 4th ed. London: John Wiley \& Son.

[3] Gillespie, T. D. 1992. Fundamentals of Vehicle Dynamics. Society of Automotive Engineers, Inc.

[4] Jazar, R. N. 2008. Vehicle Dynamics, Theory and Application. Melbourne: Springer.

[5] Romero, C. 1995. Dinámica de Tracción del automóvil. Universidad Tecnológica de Pereira, Facultad de Tecnología.

[6] Osorio, J. S., Gómez, C. S., and Restrepo, S. 2007. "Diseño y construcción de un pedal de bicicleta basado en sensores piezo resistivos para determinar la fuerza resultante.” Rev Ingeniería Biomédica 2: 55-60.

[7] Takata, N. 1995. Bicycle with electric motor. Invention patent.

[8] Suganuma, Y. 1994. Control for electric assist vehicle. Invention patent. 